\title{
Thrombokinetics in giant cell arteritis, with special reference to corticosteroid therapy
}

\author{
ANNA-LISA BERGSTRÖM, BENGT- ̊̊KE BENGTSSON, \\ LARS-BERTIL OLSSON, BO-ERIC MALMVALL, AND JACK KUTTI \\ From the Departments of Internal Medicine and Infectious Diseases, Eastern Hospital, University of \\ Gothenburg, S-416 85 Gothenburg, Sweden
}

SUMMARY Duplicate platelet survival studies were carried out on 8 patients with giant cell arteritiso (GCA), once before the institution of any therapy, and the second time when they were in a com- $\omega$ pletely asymptomatic phase after having received corticosteroid treatment. The time interval be- + tween the studies ranged between 5 and 14 months. In the first study the mean peripheral plateleto count was $486 \pm 25 \times 10^{9} / 1$ and in the second $326 \pm 25 \times 10^{9} / 1$. The difference between the means was highly significant $(\mathrm{P}<0.001)$. The mean life-span of the platelets was normal in the duplicate $e_{\subseteq}$ experiments $(6 \cdot 7 \pm 0 \cdot 3$ and $7 \cdot 3 \pm 0 \cdot 4$ days, respectively). Platelet production rate was significantly $\vec{\sigma}$ $(\mathrm{P}<0.001)$ raised in the first experiment but became normal in response to corticosteroid therapy. $\overrightarrow{0}$ It is concluded that the thrombocytosis seen in GCA is reactive to the inflammation present in thisco disease, and it seems reasonable to assume that the reduction in the peripheral platelet count which occurs in response to corticosteroid therapy accurately reflects the clinical improvement of the patient.

Thrombocytosis is frequently present in patients with untreated giant cell arteritis (GCA) (Olhagen, 1963; Hamrin, 1972; Malmvall and Bengtsson, 1978). No information is available on platelet production and platelet survival in this disease. It is well recognised that corticosteroid treatment is highly effective in GCA. However, its effects on the above mentioned parameters are unknown. In the present report we therefore provide data on platelet kinetics in a group of patients with GCA before and after the institution of corticosteroid therapy.

\section{Material and methods}

Eight consecutive patients ( 2 males and 6 females) with GCA aged 56-80 (mean 69) years were selected for study (Table 1). Six patients had histologically verified arteritis on temporal biopsies, and the remaining 2 were included according to the criteria for the diagnosis of GCA as recently described by Malmvall and Bengtsson (1978). Two of the patients had the clinical picture of temporal arteritis combined with the polymyalgia rheumatica syndrome, 2 had polymyalgia rheumatica, 2 had only general symptoms, and 2 had symptoms of localised temporal arteritis.

Accepted for publication 25 July, 1978.

Correspondence to Dr J. Kutti.
Table 1 Eight patients with GCA in whom duplicate platelet survival studies were carried out

\begin{tabular}{|c|c|c|c|c|}
\hline Patients & $\begin{array}{l}\text { Age } \\
\text { (years) }\end{array}$ & Sex & $\begin{array}{l}\text { Time interval } \\
\text { between the } 2 \\
\text { platelet survival } \\
\text { studies (months) }\end{array}$ & $\begin{array}{l}\text { Maintenance } \\
\text { oral dose of } \\
\text { prednisolone } \\
\text { during the second } \\
\text { platelet survival } \\
\text { study (mg per day }\end{array}$ \\
\hline 1 & 59 & $\mathbf{F}$ & 5 & 10 \\
\hline 2 & 71 & $F$ & 7 & 10 \\
\hline 3 & 72 & $\mathbf{F}$ & 6 & 10 \\
\hline 4 & 69 & $\mathbf{M}$ & 6 & $7 \cdot 5$ \\
\hline 5 & 72 & $\mathbf{F}$ & 6 & $2 \cdot 5$ \\
\hline 6 & 56 & $\mathbf{M}$ & 7 & $12 \cdot 5$ \\
\hline 7 & 76 & F & 14 & 10 \\
\hline 8 & 80 & $\mathbf{F}$ & 12 & 10 \\
\hline Mean & 69 & & 8 & \\
\hline
\end{tabular}

Platelet survival studies were carried out twice once before the institution of treatment and theo second time when the patients were in a completely asymptomatic phase of the disease after corticosteroid therapy. The time interval between the two studies? ranged between 5 and 14 (mean 8 ) months. During the second platelet survival study the patients? received a maintenance dose of $2 \cdot 5-12 \cdot 5 \mathrm{mg}$ pred $\stackrel{\AA}{\Omega}$ nisolone orally per day. The individual data for the patients are given in Table 1. The control group 
consisted of 8 healthy volunteers with a mean age of 56 years.

All experiments were carried out with autologous platelets. The labelling technique has been described elsewhere in detail (Kutti and Weinfeld, 1971; Kutti and Safai-Kutti, 1975). Only a brief summary of the procedure is given below.

Whole blood (approximately $250 \mathrm{ml}$ ) was collected by gravity in two plastic bags each containing $20 \mathrm{ml}$ of acid ACD (Aster and Jandl, 1964). After centrifugation of the blood (at $260 \mathrm{~g}$ ) the platelet-rich plasma (PRP) was transferred to another bag. PRP was then centrifuged (at $1600 \mathrm{~g}$ ) to provide a platelet button, which was resuspended in $10 \mathrm{ml}$ of plateletpoor plasma (PPP) and incubated with $400 \mu \mathrm{Ci}$ of ${ }^{51} \mathrm{Cr}$ in the form of sodium chromate. Thereafter the incubated platelets were washed with PPP and finally injected into the patient. Blood samples were obtained 15,30,60, and 120 min after injection of labelled platelets. Subsequent samples were drawn at $24 \mathrm{~h}$ intervals during a period of 8 days. All blood sampling was in duplicate, and platelet-bound radioactivity (PBR) was extracted from $9 \mathrm{ml}$ of venous blood as previously reported (Kutti and Weinfeld, 1971).

Platelet recovery, that is the percentage of infused PBR remaining in the peripheral blood shortly after infusion, was calculated from: PBR per ml of blood $\times B V \times 100 / P B R$ infused. BV denotes the blood volume and was calculated from height and weight measurements (Nadler et al., 1962).

Platelet mean life-span (MLS) was obtained by extrapolating the initial slope of the survival curve to the time axis (Mills, 1946; Dornhorst, 1951). This was achieved by fitting an arbitrary mathematical function:

$$
Y(x)=Y(0)\left(1-\frac{x}{T}-A\left(1-e^{-a x}\right)\right) \ldots\left\{\begin{array}{l}
0<T \\
0 \leq A \\
0<\alpha
\end{array}\right.
$$

to the experimental data by the least-squares method using a high-speed digital computer. A weight factor of 1 was applied to every experimental point. The mean of activity and time of day-zero 60 and 120 min samples was taken as the first experimental point, and subsequent data were used until about $20 \%$ of the initial activity was reached. Y (x) represents $P B R$ at time $x$ after infusion. From the parameters $Y(O), T, A$, and $\alpha, Y^{\prime}(O)$ was calculated, and platelet MLS is given by $-Y(O) / Y^{\prime}(O)$.

On the assumption of a stationary state platelet production rate $(\mathrm{P})$ equals platelet destruction rate (D) and is given by N/MLS, where $\mathrm{N}$ is the total number of circulating platelets. Consequently, $\mathrm{N}$ includes the platelets residing in the splenic pool and can be calculated from: peripheral platelet count $\times B V \times 90 \% /$ recovery $\%$, where the term
$90 \% /$ recovery $\%$ is the correction for splenic pooling of platelets (Kutti and Weinfeld, 1971).

The enumeration of platelets was carried out on venous blood by means of phase microscopy (Brecher et al., 1953). The platelet counts reported are the values obtained on day zero.

Standard statistical methods were used. Unless otherwise stated mean values \pm standard error (SE) of the mean are reported. Within the group of GCA the statistical analyses were made with Student's $t$ test and calculated on differences between matched pairs. The difference between means was considered statistically significant if $P<0 \cdot 05$ ).

\section{Results}

Peripheral platelet count. The mean peripheral platelet count at the first experiment was $486 \pm 25$ $\times 10^{9} / 1$. The corresponding mean at the second study was $326 \pm 25 \times 10^{9} / 1$, and the difference between means was highly significant $(P<0.001)$ (Tables 2 and 3). In every patient the peripheral platelet count decreased after prednisolone therapy.

Table 2 Results of platelet survival studies in 8 untreated patients with $G C A$

\begin{tabular}{llllll}
\hline Patients & $\begin{array}{l}\text { Peripheral } \\
\text { platelet } \\
\text { count } \\
(\times 109 / 1)\end{array}$ & $\begin{array}{l}\text { Platelet } \\
\text { recovery } \\
\%\end{array}$ & $\begin{array}{l}M L S \\
(\text { days })\end{array}$ & $\begin{array}{l}N \\
\left(\times 10^{10}\right)\end{array}$ & $\begin{array}{l}\text { Platelet } \\
\text { production } \\
\text { rate/day } \\
(\times 1010)\end{array}$ \\
\hline 1 & 435 & 72 & $6 \cdot 4$ & 207 & 32 \\
2 & 502 & 77 & $5 \cdot 2$ & 211 & 41 \\
3 & 415 & 75 & $6 \cdot 1$ & 189 & 31 \\
4 & 532 & 73 & $7 \cdot 4$ & 308 & 42 \\
5 & 568 & 53 & $6 \cdot 3$ & 338 & 54 \\
6 & 388 & 73 & $7 \cdot 0$ & 225 & 32 \\
7 & 577 & 82 & $6 \cdot 9$ & 215 & 31 \\
8 & 471 & 77 & $8 \cdot 2$ & 187 & 23 \\
\hline Mean & 486 & 73 & $6 \cdot 7$ & 235 & 36 \\
SD & 71 & 9 & 0.9 & 18 & 10 \\
SE & 25 & 3 & 0.3 & 6 & 3 \\
\hline
\end{tabular}

MLS = platelet mean life-span. $\mathrm{N}=$ total number of circulating platelets

Table 3 Results of platelet survival studies in 8 patients with GCA after prednisolone therapy

\begin{tabular}{llllll}
\hline Patients & $\begin{array}{l}\text { Peripheral } \\
\text { platelet } \\
\text { count } \\
\left(\times 10^{9} / 1\right)\end{array}$ & $\begin{array}{l}\text { Platelet } \\
\text { recovery } \\
(\%)\end{array}$ & $\begin{array}{l}\text { MLS } \\
(\text { days })\end{array}$ & $\begin{array}{l}N \\
\left(\times 10^{10}\right)\end{array}$ & $\begin{array}{l}\text { Platelet } \\
\text { production } \\
\text { rate/day } \\
\left(\times 10^{10}\right)\end{array}$ \\
\hline 1 & 298 & 87 & $8 \cdot 2$ & 123 & 15 \\
2 & 339 & 87 & $6 \cdot 8$ & 130 & 19 \\
3 & 189 & 89 & $7 \cdot 2$ & 78 & 11 \\
4 & 334 & 100 & $7 \cdot 2$ & 138 & 19 \\
5 & 420 & 64 & $7 \cdot 0$ & 201 & 29 \\
6 & 300 & 81 & $8 \cdot 9$ & 167 & 19 \\
7 & 397 & 80 & $5 \cdot 4$ & 161 & 30 \\
8 & 330 & 99 & $7 \cdot 8$ & 102 & 13 \\
\hline Mean & 326 & 86 & $7 \cdot 3$ & 138 & 19 \\
SD & 70 & 11 & $1 \cdot 0$ & 12 & 7 \\
SE & 25 & 4 & 0.4 & 4 & 2 \\
\hline
\end{tabular}

MLS = platelet mean life-span. $\mathrm{N}=$ total number of circulating platelets. 
Platelet recovery. Fig. 1 shows the circulating PBR $2 \mathrm{~h}$ after infusion in the duplicate experiments. It is seen that the values for platelet recovery in the second experiment were considerably higher than in the first, and the difference was statistically significant $(P<0.005)$.

The individual values for platelet recovery given in Tables 2 and 3 denote the highest value obtained at 60 or $120 \mathrm{~min}$. The mean platelet recovery in the control group was $73 \pm 4 \%$.

Platelet mean life-span (Tables 2 and 3). The average platelet MLS before treatment was $6 \cdot 7 \pm$ $\mathbf{0 . 3}$ days. After corticosteroid therapy the corresponding value was slightly higher $(7 \cdot 3 \pm 0 \cdot 4)$, but there was no statistical difference between the means. The mean platelet MLS in the control group was $6 \cdot 6 \pm 0 \cdot 5$ (range $4 \cdot 5-8 \cdot 7$ days).

Platelet production rate (Tables 2 and 3). In the first study the mean for $P$ was $36 \pm 3 \times 10^{10}$ platelets per day. In response to prednisolone therapy in every subject there was a fall in P. The mean for $P$ at the second study $\left(19 \pm 2 \times 10^{10}\right)$ was significantly lower $(P<0.001)$ and did not differ from the control mean $\left(21 \pm 2 \times 10^{10}\right)$.

\section{Discussion}

In this study the raised values for the peripheral platelet counts in untreated patients with GCA were explained by increased platelet production. Pred-

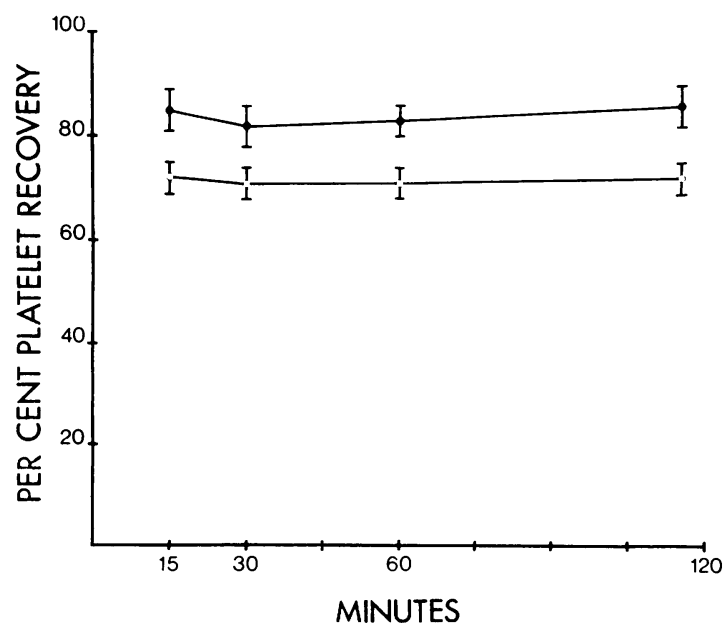

Fig. 1 Initial platelet recovery in 8 patients with GCA in whom duplicate platelet survival studies were performed. In the first study $(\mathrm{O}-\mathrm{O})$ the patients received no therapy. In the second study (Othe patients were on prednisolone therapy. The symbols denote mean values $\pm S E$. nisolone treatment significantly reduced the perit pheral platelet concentration. Platelet MLS was? shown to be normal in untreated patients and was unaffected by corticosteroids.

It is generally accepted that disorders associated with thrombocytosis may be designated as eithete reactive or autonomous (Harker and Finch, 1969) Reactive thrombocytosis may occur with, for example inflammation, iron deficiency, or neoplasia nots arising from haemopoietic tissue (Harker and Finch $\overrightarrow{0}$ 1969). Autonomous thrombocytosis on the other handis the term applied to an increased peripheraf platelet count associated with neoplastic proliferation of the megakaryocytes as characteristically seen in the so-called myeloproliferative disorders, fow example, primary thrombocythaemia, polycyth aemia vera, myelofibrosis with myeloid metaplasia and chronic granulocytic leukaemia (Harker and Finch, 1969; Kutti and Weinfeld, 1971; Kutti et al., 1973; Weinfeld et al., 1975). Hence, in accordance with the above findings the thrombocytosis seen in GCA should be regarded as reactive to the inflammation present in this disease.

Before the institution of therapy $P$ was about $1 \cdot 70$ times higher than in the controls. After corticosteroid treatment, when the GCA patients were studied in an asymptomatic phase, $\mathbf{P}$ was shown to have become normal. This depression of $\mathbf{P}$ was reflected by the overall lowering in the peripheral platele $\mathbb{D}$ concentration. It therefore seems that the reduction in the platelet count which occurs in response tof corticosteroid therapy reflects clinical improvement, as do other laboratory tests such as the ESR ande levels of fibrinogen and haptoglobin.

As shown in Fig. 1, the values for platelet recovery, an indirect measure of the size of the exchangeable splenic platelet pool (ESPP), were significantly? raised in the second experiment. This is an interesting? observation, but it is not easily explained. It is tempting to speculate that corticosteroid therapy affects the magnitude of the ESPP. On the other hand the possibility cannot be excluded that the disorder itself, despite corticosteroid therapy compromises the splenic microcirculation, so that the ESPP is reduced. This study was supported by grants from Riksförbundet mop Reumatism and Gothenburg Medical Society. The authors wish to thank Miss Marianne Dahlberg for skilful technicaE assistance.

\section{References}

Aster, R. H., and Jandl, J. H. (1964). Platelet sequestration in man. I. Methods. Journal of Clinical Investigation, $43 \stackrel{\frac{\mathrm{Q}}{\mathrm{D}}}{\mathrm{P}}$

Brecher, G., Schneiderman, M., and Cronkite, E. P. (1953) The reproducibility and constancy of the platelet count American Journal of Clinical Pathology, 23, 15-26. 
Dornhorst, A. C. (1951). The interpretation of red cell survival curves. Blood, 6, 1284-1292.

Hamrin, B. (1972). Polymyalgia arteritica. Acta Medica Scandinavica, Suppl. 553, 103-105.

Harker, L. A., and Finch, C. A. (1969). Thrombokinetics in man. Journal of Clinical Investigation, 48, 963-974.

Kutti, J., and Weinfeld, A. (1971). Platelet survival in man. Scandinavian Journal of Haematology, 8, 336-346.

Kutti, J., Ridell, B., Weinfeld, A., and Westin, J. (1973). The relation of thrombokinetics to bone marrow megakaryocytes and to the size of the spleen in polycythaemia vera. Scandinavian Journal of Haematology, 10, 88-95.

Kutti, J., and Safai-Kutti, S. (1975). In vitro labelling of platelets: an experimental study on healthy asplenic subjects using two different incubation media. British Journal of Haematology, 31, 57-64.

Malmvall, B.-E., and Bengtsson, B.-Å. (1978). Giant cell arteritis, clinical features and involvement of different organs. Scandinavian Journal of Rheumatology (in press).

Mills, J. N. (1946). The life span of the erythrocyte. Journal of Physiology, 105, 16-17P.

Nadler, S. B., Hidalgo, J. U., and Block, T. (1962). Prediction of blood volume in normal human adults. Surgery, 51, 224-232.

Olhagen, B. (1963). Polymyalgia rheumatica a form of senile arteritis? Acta Rheumatologica Scandinavica, 9, 157-164. Weinfeld, A., Branehög, I., and Kutti, J. (1975). Platelets in the myeloproliferative syndrome. Clinics in Haematology, 4, 373-392. 